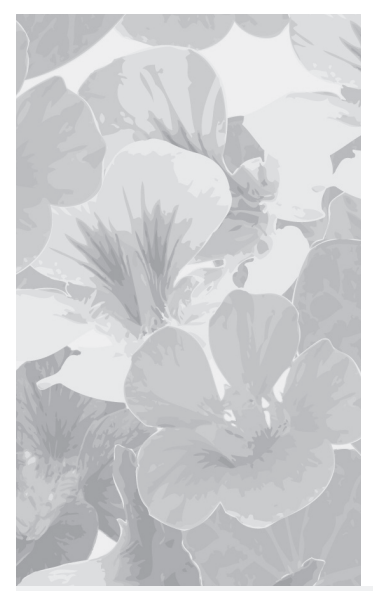

\title{
Wyprysk z podrażnienia mechanicznego jako powikłanie po mikrodermabrazji korundowej
}

\author{
Friction dermatitis as a complication after corundum microdermabrasion \\ Jadwiga Wojtanowska, Magdalena Niewęgłowska-Wilk, Radosław Śpiewak \\ Zakład Dermatologii Doświadczalnej i Kosmetologii, Wydział Farmaceutyczny, \\ Uniwersytet Jagielloński Collegium Medicum, Kraków \\ Estetol Med Kosmetol 2012; 2(2): 63-65 \\ DOI: http://dx.doi.org/10.14320/EMK.2012.013
}

\begin{abstract}
The case is described of 27-year-old woman with no previous skin problems, who decided on a series of corundum microdermabrasion treatments. The device was set at the average abrasion power (grade 12 on the arbitrary scale of the device). Approximately 10-12 hours after the first treatment, the woman noticed an intense redness and a burning sensation of the skin. The treating cosmetologist insisted that the reaction was normal and recommended that the woman should continue with the treatments, with the power reduced, however, to grade 9. After three treatments, the patient decided to discontinue the procedure because of intense erythema and increased tenderness of her skin. The skin returned to normal about four weeks later. Based on the clinical symptoms, friction dermatitis was deemed the most probable diagnosis. Corundum microdermabrasion is a beauty treatment intended to exfoliate the keratinized epidermis with the use of corundum grains. This treatment often causes discomfort to patients. According to a previous study, cosmetologists frequently encounter complications after applying this method, such as skin irritation, intense redness of skin or excessive exfoliation. However, to our knowledge, this is a first published report of friction dermatitis of the face due to corundum microdermabrasion. Users of microdermabrasion should be aware of the risk of adverse reactions such as the one describe here.
\end{abstract}

Keywords: corundum microdermabrasion, exfoliation of the skin, adverse effects, friction dermatitis

Stowa kluczowe: mikrodermabrazja korundowa, złuszczanie skóry, działania niepożądane, wyprysk z podrażnienia mechanicznego

Copyright @ 2012 the Authors (text) and Radostaw Śpiewak (layout \& journal compilation). All rights reserved.

27-letnia kobieta, nie mająca aktualnie problemów ze skórą, zdecydowała się na serię zabiegów mikrodermabrazji korundowej twarzy. Przed wykonaniem pierwszego zabiegu odbyła rutynową konsultację kosmetologiczną w celu ustalenia parametrów zabiegu oraz doboru odpowiednich preparatów pielęgnacyjnych. Przy pierwszym zabiegu, aparat „Hebe” został nastawiony na średnią moc ścierania, która w arbitralnej, niemianowanej skali używanego urządzenia wynosiła 12, czas zabiegu ustalono na 10 minut. Po upływie 10-12 godzin, u pacjentki w miejscu zabiegu wystąpił silny rumień utrzymujący się przez kilka dni, któremu towarzyszyła wzmożona tkliwość i wrażenie palenia skóry. Stan skóry po pierwszym zabiegu: na obu policzkach pojawił się rozlany rumień, a w jego obrębie wyraźnie zaznaczały się czerwone pasma obrzęku odpowiadające kierunkowi przebiegu głowicy aparatu do mikrodermabrazji korundowej (ryc. 1). Po upływie 24 godzin skóra nadal była mocno podrażniona, pojawiło się ponadto mierne, otrębiaste złuszczanie (ryc. 2). W okolicach jarzmowych skóra była wyraźnie napięta, błyszcząca, z obecnością grudek obrzękowych na intensywnie rumieniowym podłożu (ryc. 3). Prowadzący zabieg kosmetolog stwierdził, iż reakcja taka może wystąpić i zalecił kontynuację zabiegów, zmniejszając jedynie moc zabiegu do 9 stopni na skali aparatu. Efekt kosmetyczny był satysfakcjonujący, jednak pacjentka nadal skarżyła się na wzmożoną wrażliwość skóry oraz lekkie jej zaczerwienienie.
Kosmetolog ciągle zapewniał ją o „normalnym” efekcie zabiegu i zachęcał do kontynuacji serii zabiegów. Po 3 zabiegach pacjentka jednak zrezygnowała, a skóra wróciła do normalnego wyglądu po około 4 tygodniach.

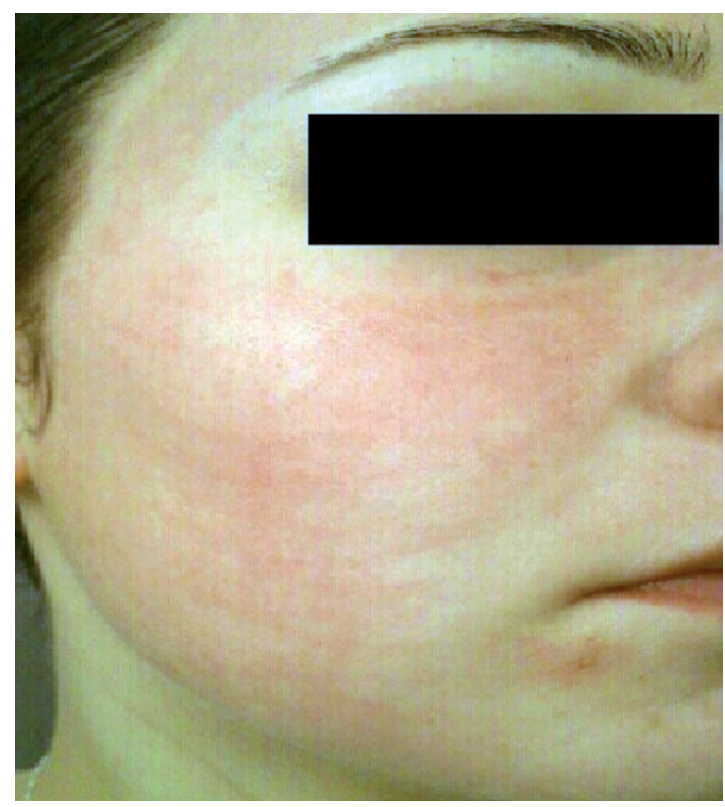

Rycina 1. Stan skóry 12 h po pierwszym zabiegu mikrodermabrazji korundowej 


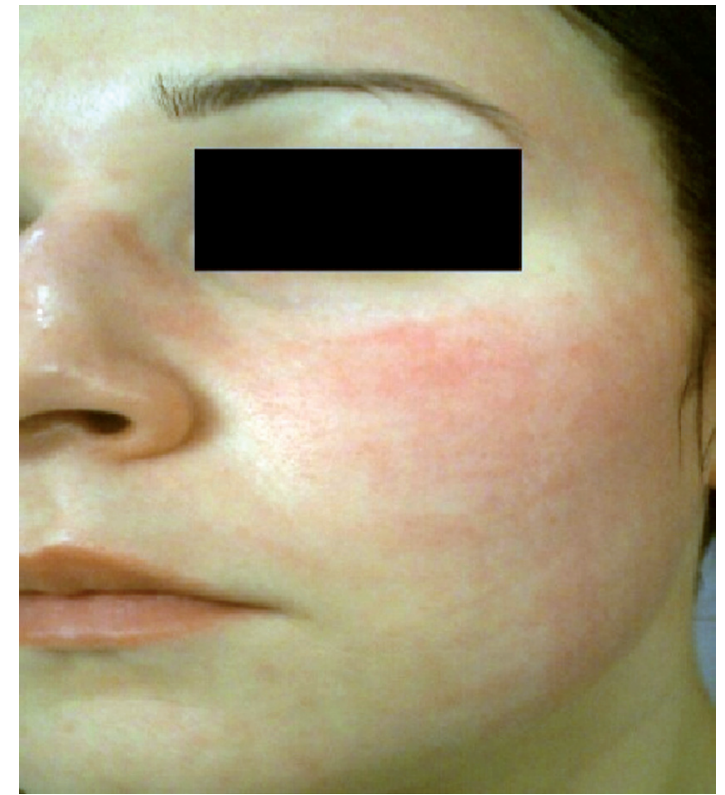

Rycina 2. Stan skóry 24 h po pierwszym zabiegu mikrodermabrazji korundowej

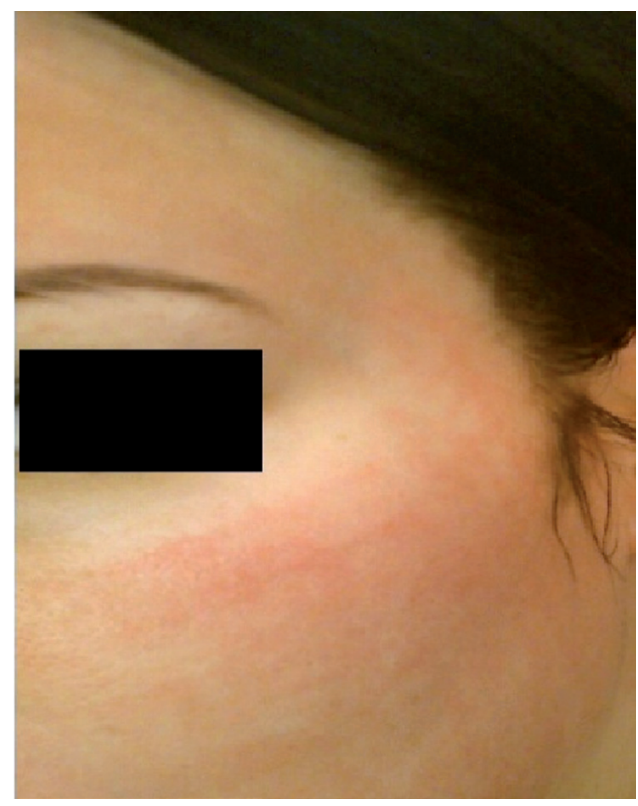

Rycina 3. Stan skóry w okolicy jarzmowej 24 h po wykonanym zabiegu

\section{Dyskusja}

Mikrodermabrazja jest zabiegiem kosmetycznym zaliczanym do peelingów mechanicznych, stosowanym w celu kontrolowanego złuszczania zrogowaciałego naskórka. Rozróżnia się trzy rodzaje mikrodermabrazji: diamentową, korundową oraz wodno-tlenową. Każda z nich opiera się na zastosowaniu innego materiału ściernego i techniki aplikacji, różna jest także intensywność zabiegu oraz głębokość złuszczenia naskórka. W mikrodermabrazji korundowej do złuszczania zrogowaciałego naskórka wykorzystuje się zmikronizo- wane kryształy korundu wyrzucane pod ciśnieniem z dyszy aparatu [1]. Ze względu na właściwości bakteriobójcze korundu zabieg polecany jest szczególnie osobom cierpiącym na trądzik pospolity [2]. Ponadto mikrodermabrazję korundową wykorzystuje się w eliminacji szorstkości skóry, hiperpigmentacji, plam starczych oraz przebarwień posłonecznych, a także powierzchownych blizn. Nie poleca się jej natomiast osobom ze skórą cienką i wrażliwą, tendencją do bliznowacenia, teleangiektazjami, trądzikiem różowatym czy też aktywną infekcją w miejscu zabiegu [3-6]. Według badań przeprowadzonych w 2011 roku, kosmetolodzy najczęściej stosują mikrodermabrazję diamentową, która w ich przekonaniu jest zabiegiem bezpiecznym i nie dającym powikłań w postaci rumienia i podrażnień skóry, natomiast najrzadziej wybierają mikrodermabrazję korundową ze względu na większe ryzyko powikłań [1]. Zabieg mikrodermabrazji korundowej często powoduje dyskomfort u pacjentek, niekiedy obserwuje się poważniejsze powikłania pozabiegowe. Dlatego osoby korzystające z mikrodermabrazji korundowej powinny zawsze być informowane o ryzyku podrażnienia i zaczerwienienia skóry.

U opisanej pacjentki obraz kliniczny wskazuje na wyprysk z podrażnienia na skutek bodźca mechanicznego. Przemawia za tym zarówno czas wystąpienia zmian i utrzymywania się ich na skórze, jak i obraz kliniczny [7,8]. W diagnostyce różnicowej należało również uwzględnić pokrzywkę opóźnioną z ucisku i dermografizm, jednak utrzymywanie się zmian ponad $2 \mathrm{dni}$, niewielki miejscowy obrzęk, mierny świąd oraz brak w wywiadzie osobniczym podobnych epizodów $\mathrm{w}$ innych sytuacjach przemawiały przeciw tym rozpoznaniom. W literaturze medycznej można znaleźć opis przypadku zlokalizowanego na kciukach wyprysku z podrażnienia prowokowanego przez mechaniczne tarcie o materiał rajstop [9] oraz przypadek bejsbolisty z wypryskiem powstałym na skutek tarcia skóry w okolicy stawu skokowego i kolana [10]. Jak dotąd nie opisano natomiast wyprysku z podrażnienia mechanicznego zlokalizowanego na twarzy. Jest to zarazem pierwszy opis wyprysku z podrażnienia na skutek mikrodermabrazji, choć na podstawie wypowiedzi kosmetologów można wnioskować, że przypadki podrażnienia skóry w trakcie mikrodermabrazji korundowej wcale nie są rzadkie.

\section{Piśmiennictwo}

1. Kordus K, Potempa B, Śpiewak R: Badania motywów wyboru rodzajów mikrodermabrazji oraz opinii o ich skuteczności w praktyce kosmetologicznej. Estetol Med Kosmetol 2011; 1(1):21-5.

2. Savardekar P: Microdermabrasion. Indian J Dermatol Venereol Leprol 2007; 73(4):277-9. 
3. Bhalla M, Thami GP: Microdermabrasion: Reappraisal and brief review of literature. Dermatol Surg 2006; 32(6): 809-14.

4. Spences JM: Approaches to document the efficacy and safety of microdermabrasion procedure. Dermatol Surg 2006; 32(11):1353-7.

5. Small R: Aesthetic procedures in office practice. Am Fam Physician 2009; 80(11):1231-7.

6. Karimipour DJ, Karimipour G, Orringer JS: Microdermabrasion: an evidence-based review. Plast Reconstr Surg 2010; 125(1):372-7.

7. Śpiewak R: Alergia kontaktowa i alergiczny wyprysk kontaktowy. W: Fal AM, red. Alergie, choroby alergiczne, astma. Medycyna Praktyczna, Kraków 2011:371-91.

8. Śpiewak R. Pesticides and skin diseases in man. In: Rathore H, Nolet LM, editors. Pesticides: Evaluation of Environmental Pollution. CRC Press, Boca Raton 2012: 525-42.

9. Gould WM: Friction dermatitis of the thumbs caused by pantyhose. Arch Dermatol 1991; 127(11):1740.

10. Inui S, Yamamoto S, Ikegami R, Ozawa K, Itami S, Yoshikawa K: Baseball pitcher's friction dermatitis. Contact Dermatitis 2002; 47(3):176-7.

\section{Finansowanie i konflikt interesów}

Przygotowanie niniejszej publikacji zostało w całości sfinansowane z własnych środków autorów. Wszyscy autorzy deklarują niewystępowanie konfliktu interesów $\mathrm{w}$ odniesieniu do treści zawartych w niniejszej pracy.

\section{Adres do korespondencji}

mgr Jadwiga Wojtanowska

Zakład Dermatologii Doświadczalnej i Kosmetologii UJ ul. Medyczna 9, 30-688 Kraków

Tel.: 1262058 30, Fax: 126205645

E-mail: j.wojtanowska@uj.edu.pl

Data złożenia: 4.04 .2012

Data akceptacji: 21.04.2012

Data aktualizacji: 30.11 .2012

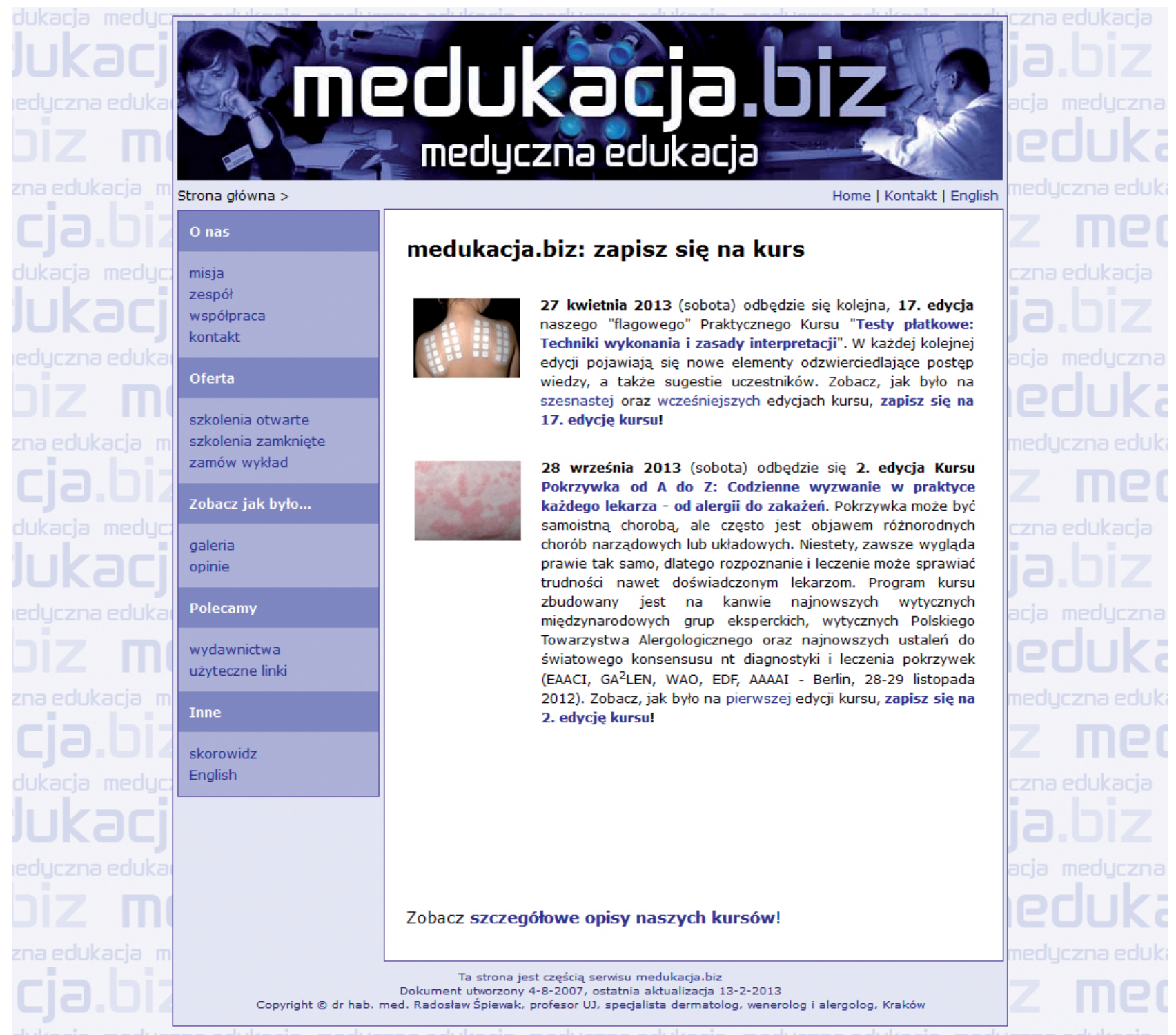

